Supplement of

\title{
Constraining uncertainties in particle-wall deposition correction during SOA formation in chamber experiments
}

Theodora Nah et al.

Correspondence to: Nga L. Ng (ng@ chbe.gatech.edu)

The copyright of individual parts of the supplement might differ from the CC-BY 3.0 licence. 

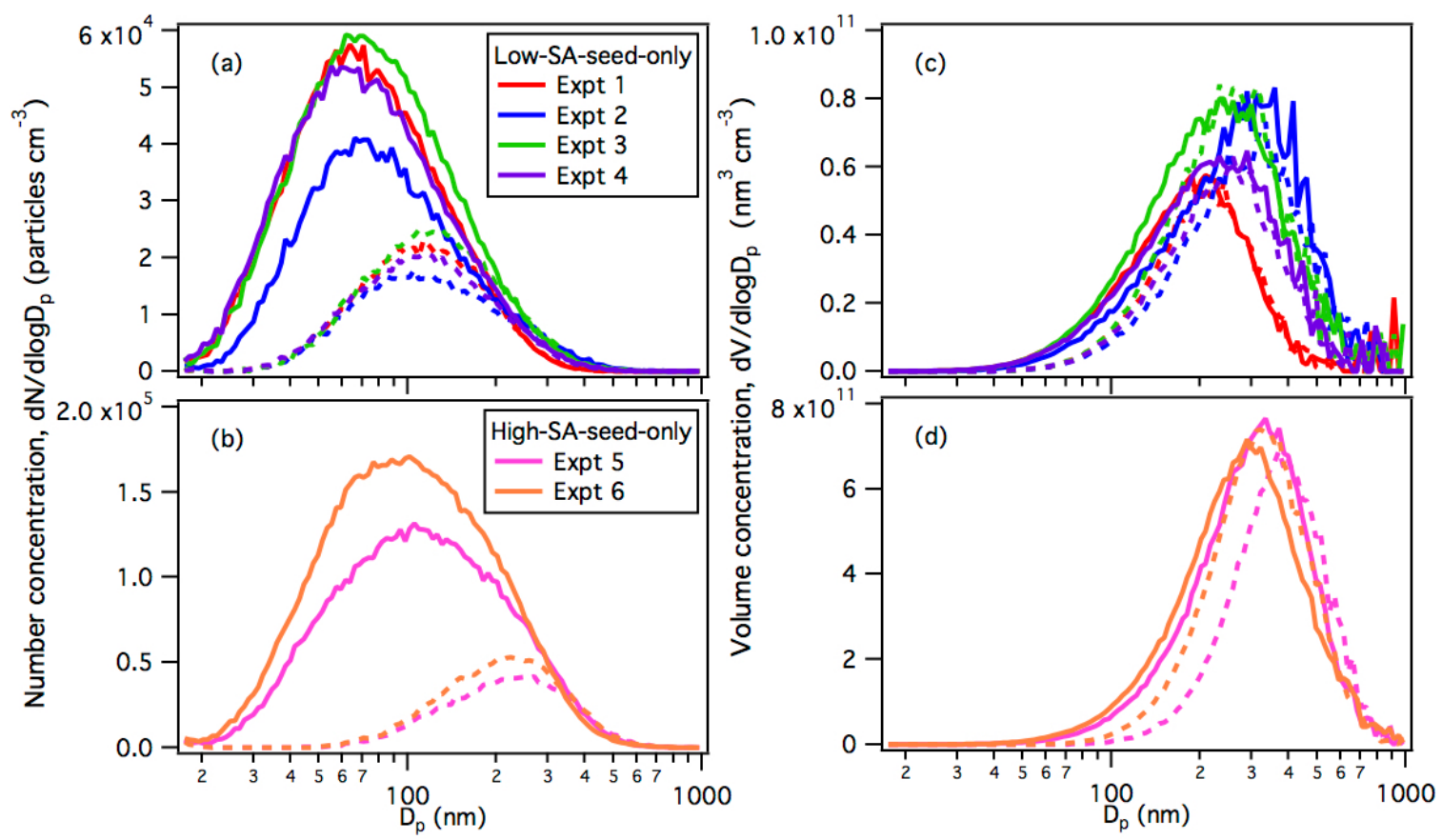

23 Figure S1: Initial (solid lines) and final (420 min later, dashed lines) number and volume 24 size distributions during the low-SA-seed-only (panels (a) and (c)) and high-SA-seed-only 25 (panels (b) and (d)) experiments. Refer to Table 1 for information on the AS solution(s) 26 used to generate the seed aerosol and the initial seed aerosol surface area concentrations in 27 these experiments. 


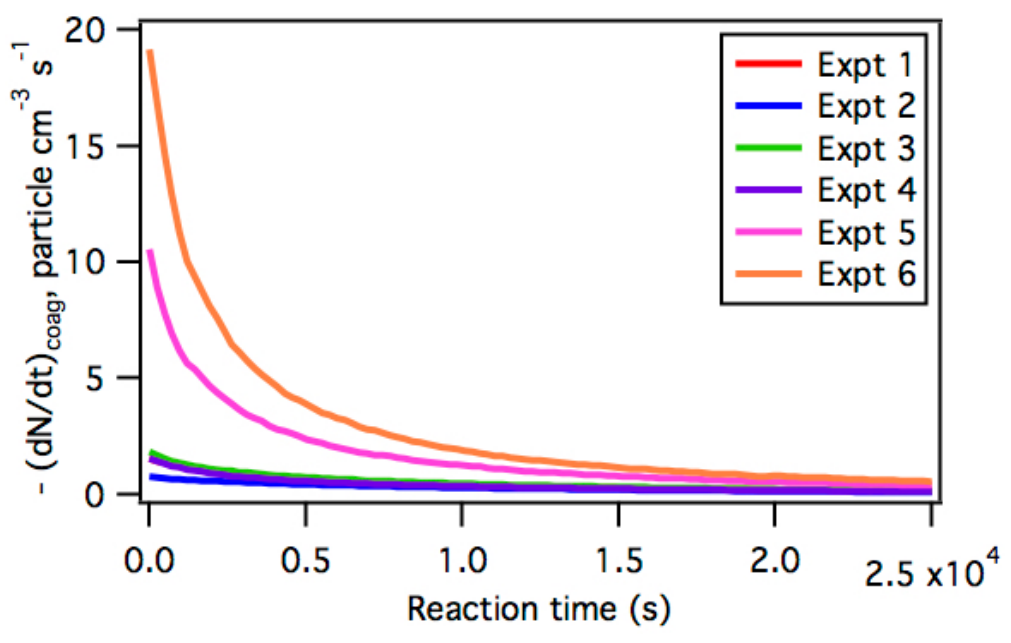

35 Figure S2: Change in total particle number concentration due to coagulation alone as a 36 function of reaction time for the seed-only experiments. These results are obtained from

37 the aerosol-dynamics model using the raw time-dependent number distribution data

38 measured by the SMPS during seed-only experiments and coagulation coefficients

39 calculated from Table 13.1 in Seinfeld and Pandis (2016). 

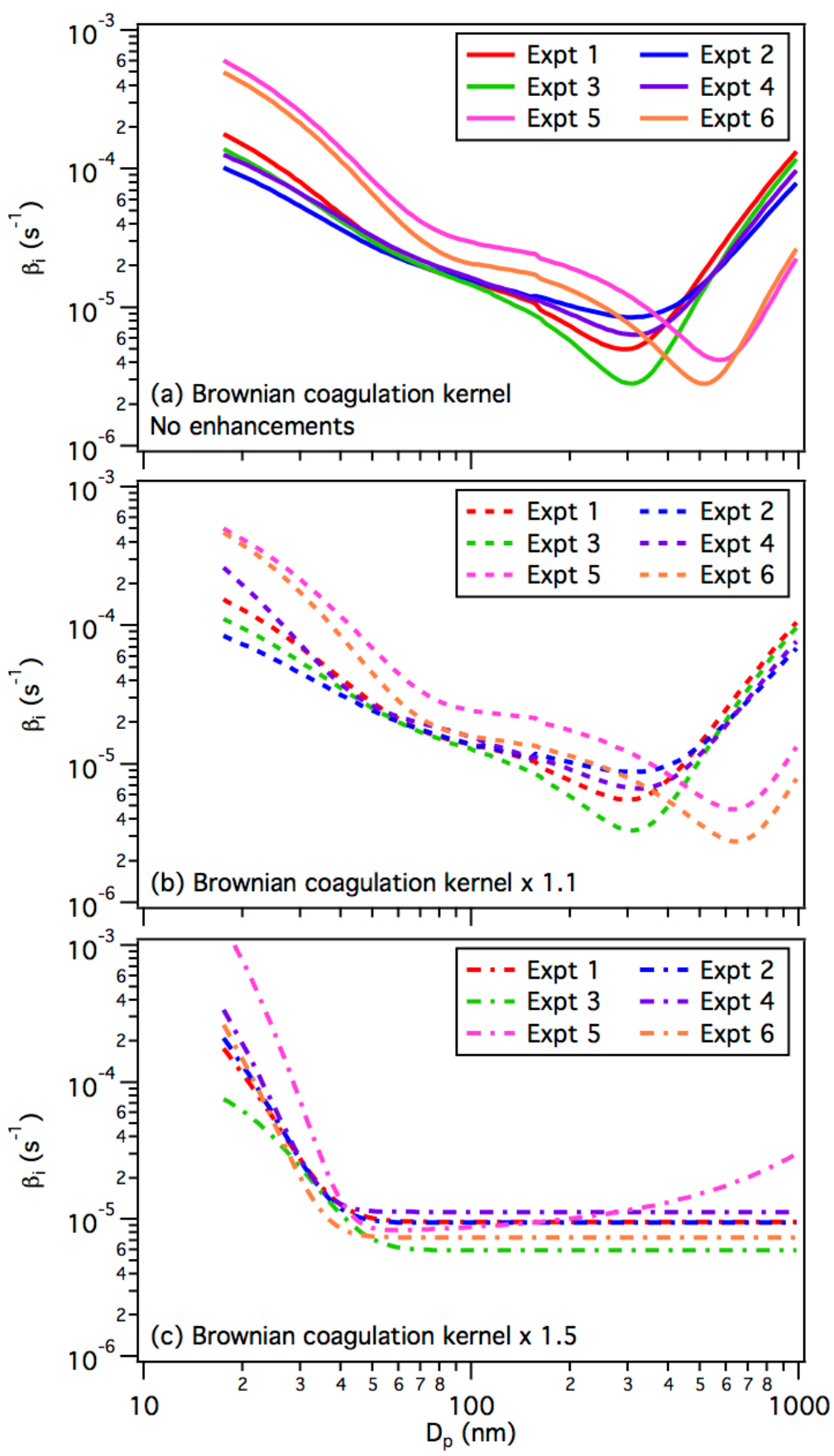

48 Figure S3: Coagulation-corrected particle wall-deposition coefficients $\left(\beta_{i}\right)$ for seed-only 49 experiments. In panel (a), the coagulation-corrected particle wall-deposition coefficients 50 are obtained using the Brownian coagulation kernel calculated from Table 13.1 in Seinfeld 51 and Pandis (2016). In panels (b) and (c), the Brownian coagulation kernel is scaled by 1.1 52 and 1.5 uniformly across all particle sizes, respectively. 

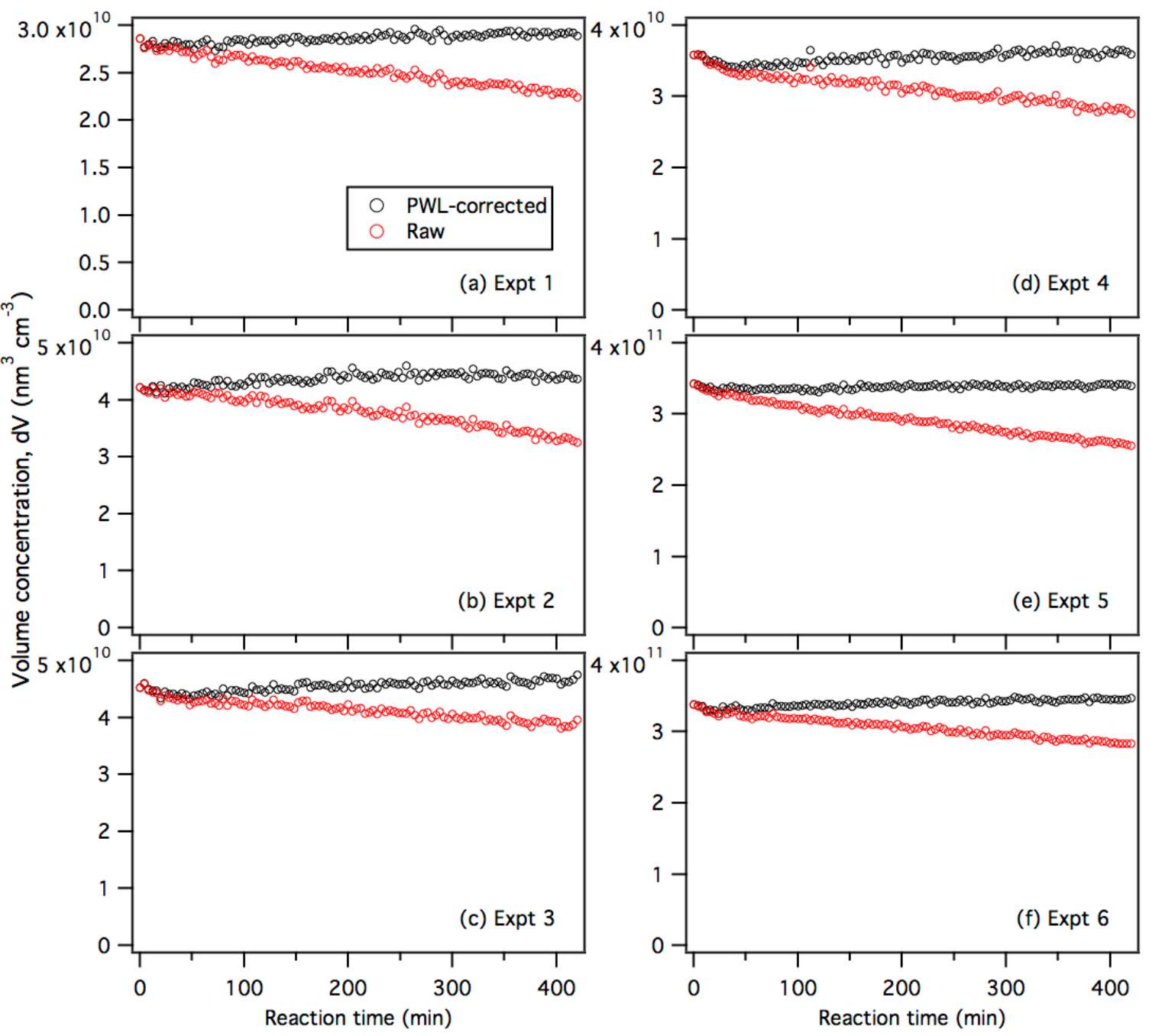

Figure S4: Raw (red) and particle wall-loss-corrected (black) volume concentrations as a 55 function of reaction time for the low-SA-seed-only and high-SA-seed-only experiments.

56 Coagulation-corrected size-dependent particle wall-deposition coefficients are used to 57 correct for particle wall-deposition in the analysis shown here. Refer to Table 1 for 58 information on the AS solution(s) used to generate the seed aerosol and the initial seed 59 aerosol surface area concentrations in these experiments. 

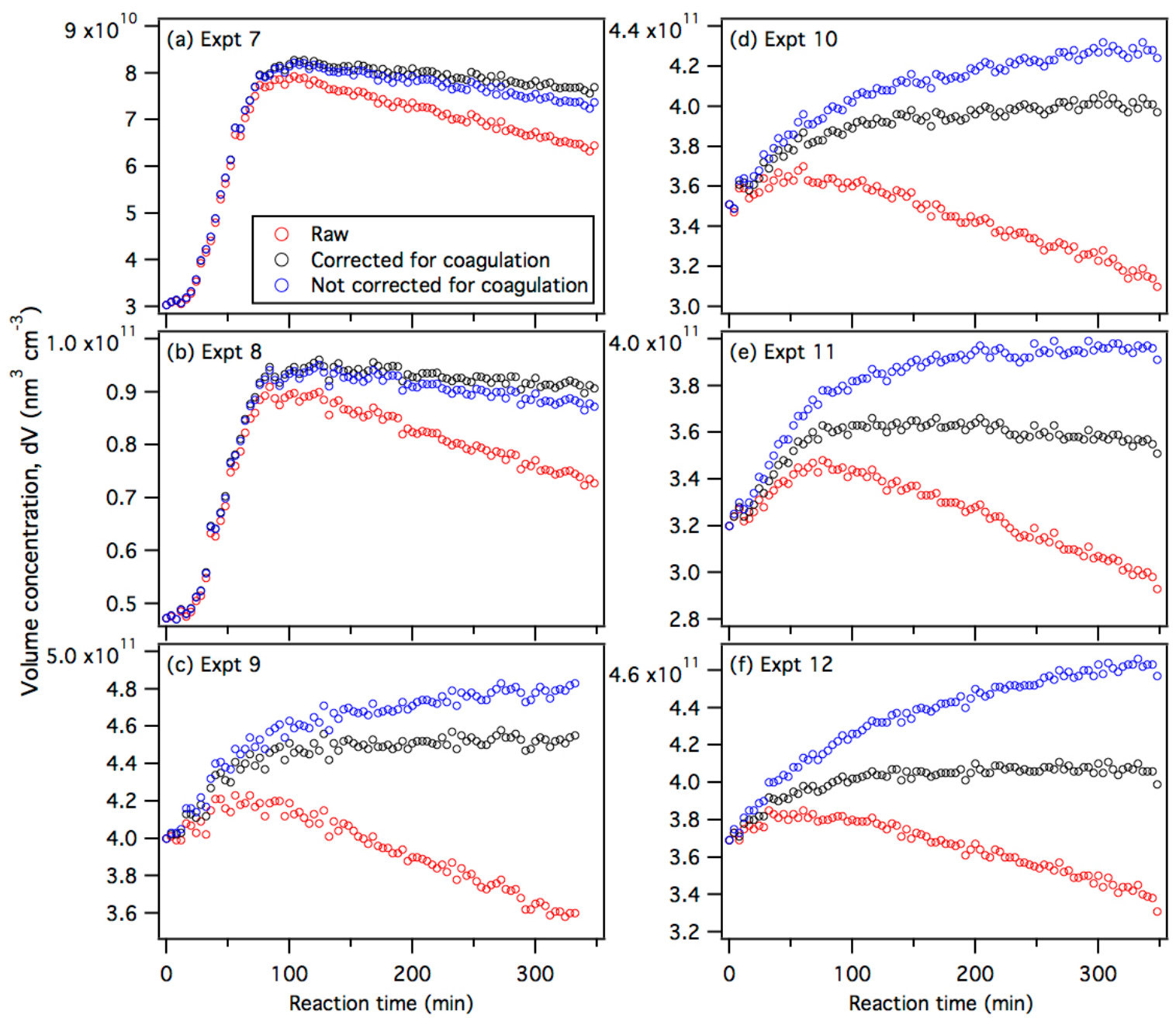

Figure S5: Raw (red) and particle wall-deposition-corrected volume concentrations for the

$62 \alpha$-pinene ozonolysis experiments. The uncorrected (blue) and coagulation-corrected 63 (black) size-dependent particle wall-deposition coefficients are used to correct for particle 64 wall-deposition in the analyses shown here. 


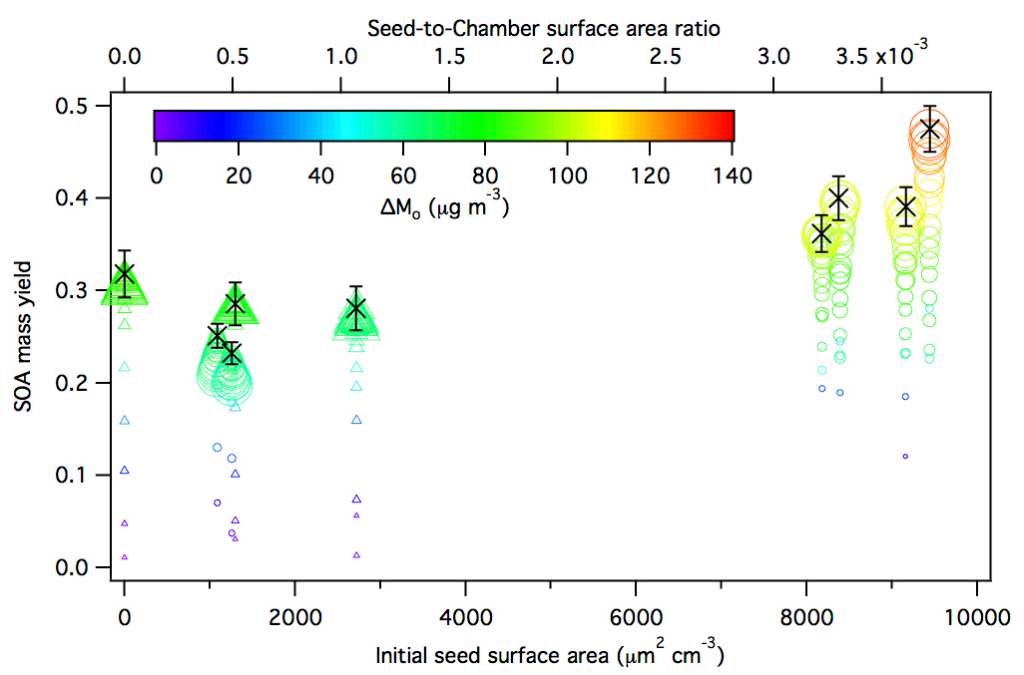

67 Figure S6: Averaged SOA mass yields over the course of an $\alpha$-pinene ozonolysis 68 experiment as a function of initial total AS seed aerosol surface area concentration. Results

69 from this study (15 min-averaged) are shown as circles, while results from the study by

70 Nah et al. (2016) (10 min-averaged) are shown as triangles. All the SOA mass yields shown 71 here (this study and the study by Nah et al. (2016)) are obtained using the uncorrected size72 dependent particle wall-deposition coefficients (that do not account for coagulation). 73 Symbol color indicates the SOA mass concentration and symbol size indicates the time 74 after $\mathrm{O}_{3}$ is injected into the chamber. The $\times$ symbols are the SOA mass yields at peak SOA 75 growth obtained from the experimental data. The y-axis error bars represent the uncertainty 76 in the SOA mass yield at peak SOA growth, which originates from the $\alpha$-pinene injection 77 and the aerosol mass concentration at peak SOA growth (one standard deviation). 

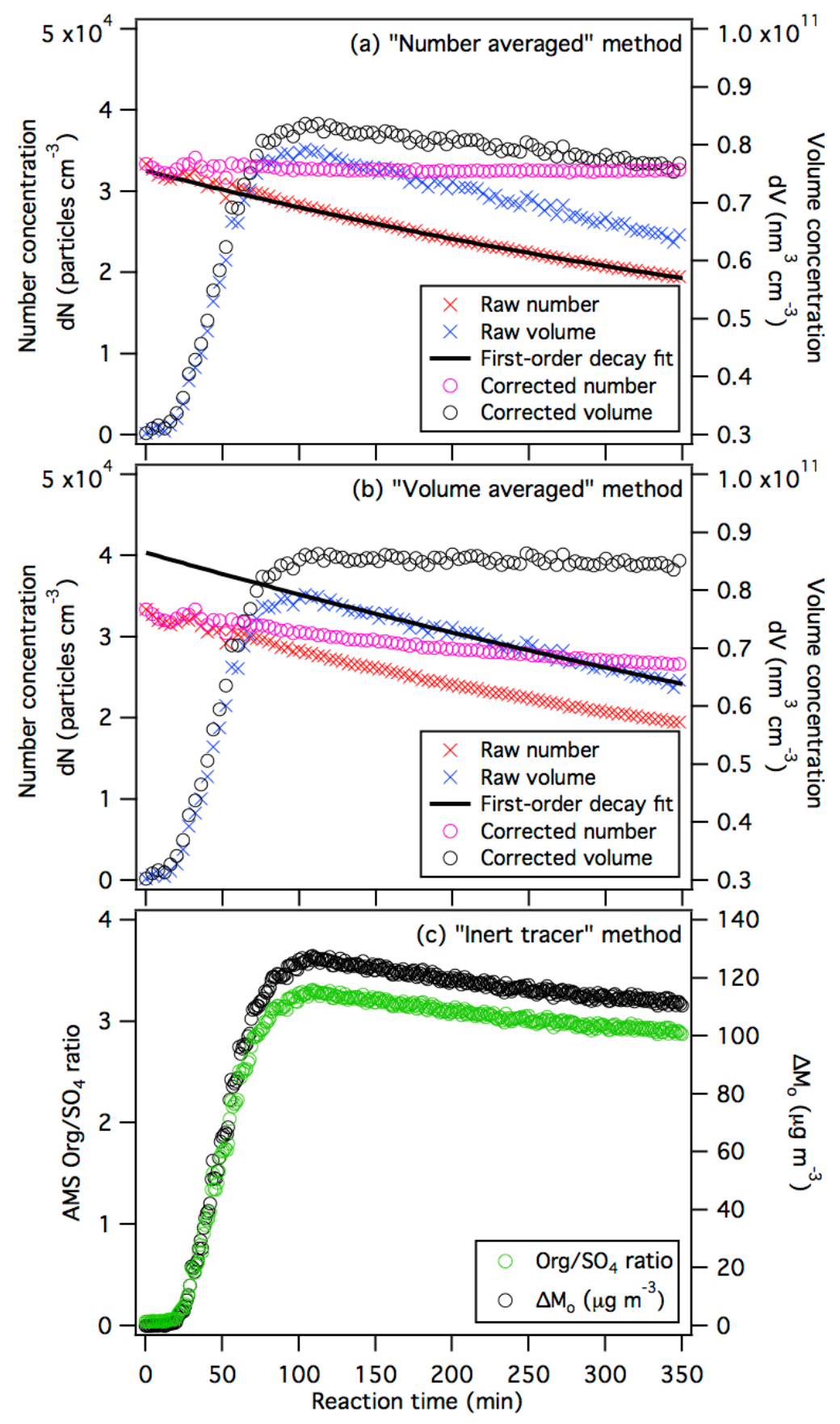

79 Figure S7: Example of particle wall-deposition rate calculation and correction (experiment

80 7) using the (a) "number averaged", (b) "volume averaged" and (c) "inert tracer" particle

81 wall-deposition correction methods. The "number averaged" and "volume averaged"

82 methods apply the first-order decay fits of the raw number and volume concentrations,

83 respectively, to the entire experiment to account for particle wall-deposition. The "inert

84 tracer method" uses the organic-to-sulfate $\left(\mathrm{Org} / \mathrm{SO}_{4}\right)$ ratio obtained from HR-ToF-AMS

85 measurements to determine the SOA mass concentration. 
87 Table S1: Initial and particle wall-deposition-corrected final total volume concentrations 88 for seed only experiments $^{\mathrm{a}}$

\begin{tabular}{|c|c|c|c|c|c|}
\hline Expt & AS seed conditions & $\begin{array}{l}\text { Initial Seed } \\
\text { aerosol } \\
\text { surface area } \\
\left(\mu \mathrm{m}^{2} \mathrm{~cm}^{-3}\right)\end{array}$ & $\begin{array}{l}\text { Initial } \\
\text { Volume } \\
\text { Concentration } \\
\left(\mathrm{nm}^{3} \mathrm{~cm}^{-3}\right)\end{array}$ & $\begin{array}{l}\text { Final } \\
\text { Volume } \\
\text { Concentration } \\
\left(\mathrm{nm}^{3} \mathrm{~cm}^{-3}\right)^{\mathrm{b}}\end{array}$ & $\begin{array}{c}\% \\
\text { Change }\end{array}$ \\
\hline 1 & $0.015 \mathrm{M} \mathrm{AS}$ & 1090 & $2.86 \times 10^{10}$ & $2.89 \times 10^{10}$ & 1.0 \\
\hline 2 & $0.05 \mathrm{M} \mathrm{AS}$ & 0 & $4.22 \times 10^{10}$ & $4.37 \times 10^{10}$ & 3.6 \\
\hline 3 & $0.015 \mathrm{M} \& 0$ & & $4.53 \mathrm{x}$ & $4.75 \times 10^{10}$ & 4.9 \\
\hline 4 & 0.0 & & $3.58 \mathrm{x}$ & $3.59 \times 10^{10}$ & 0.3 \\
\hline 5 & $0.05 \mathrm{M} \mathrm{AS}$ & 8000 & $3.43 \mathrm{x}$ & $3.4 \times 10^{11}$ & -0.9 \\
\hline 6 & $0.015 \mathrm{M} \& 0.05 \mathrm{M} A S$ & 8580 & $3.38 \times 10^{11}$ & $3.47 \times 10^{11}$ & 2.7 \\
\hline & \multicolumn{5}{|l|}{ Particle volume concentration } \\
\hline & \multirow{4}{*}{\multicolumn{5}{|c|}{$\begin{array}{l}{ }^{b} \text { The data shown here correspond to those shown in Fig. S4. The data have been particle } \\
\text { wall-deposition-corrected using coagulation-corrected particle wall-deposition coefficients } \\
\text { (with no enhancement to the coagulation rates) determined using the aerosol-dynamics } \\
\text { model (described in section 3) and the experimental data. }\end{array}$}} \\
\hline & & & & & \\
\hline 92 & & & & & \\
\hline 93 & & & & & \\
\hline 4 & \multicolumn{5}{|c|}{$c_{\%}$ Change $=\frac{\text { (Difference between initial and particle wall-loss-corrected final number concentration) }}{} \times 100 \%$} \\
\hline
\end{tabular}

